\title{
Embracing Ethical Fields: Constructing Consumption in the Margins
}

\author{
Full citation of Article: Shaw, D. and Riach, K. (2011) 'Embracing Ethical Fields: Constructing
}

Consumption in the Margins', European Journal of Marketing, 45(7/8): 1051-1067.

\begin{abstract}
Purpose

Literature examining resistant consumer behaviour from an ethical consumption stance has increased over recent years. This paper argues that the conflation between ethical consumer behaviour and 'anti-consumption' practices results in a nihilistic reading and fails to uncover the tensions of those who seek to position themselves as ethical whilst still participating in the general market.
\end{abstract}

\section{Design/methodology/approach}

The study adopts an exploratory approach through semi-structured in-depth interviews with a purposive sample of 7 ethical consumers.

\section{Findings}

The analysis reveals the process through which ethical consumption is constructed and defined in relation to the subject position of the 'ethical consumer' and their interactions with the dominant market of consumption.

\section{Research limitations/implications}

This research is limited to a single country and location and focused on a specific consumer group. Expansion of the research to a wider group would be valuable. 


\section{Practical implications}

The impact of ethical consumption on the wider field of consumption can be witnessed in the 'mainstreaming' of many ethical ideals. This highlights the potential movements of power between various stakeholders that occupy particular spaces of social action.

\section{Originality/value}

Understanding the analysis through Bourdieu's concepts of field and the margins created between spaces of consumption we focus on the theoretical cross-section of practice between ethical and market-driven forms of consumption, advancing discussion by exploring how self-identified 'ethical consumers' defined, legitimatised and negotiated their practices in relation to consumption acts and lifestyles.

\section{Keywords}

Anti-consumption, ethical consumption, consumer decision-making, Bourdieu.

\section{Classification}

Research Paper

\section{Introduction}

While the literature exploring ethically concerned consumers has increased significantly over recent years, much of this literature has explored ethical consumption from the perspective of consumers resisting the market. This can be witnessed in the many terms which have been used to describe such consumer acts 
including, consumer resistance, boycotting, consumer rebellion, counter-cultural movements and non-consumption (see Cherrier, 2008). We advocate that rather than viewing ethical consumption as against the market, its theorization should focus on its relationship with the market and wider consumption practices. Whilst individuals may have developed a particular set of beliefs, opinions and values relating to ethical consumption, they are also required to interact within the larger social setting of the market where conflicting views dominate and can result in strained interactions. Not only does this require reflection on the part for the individual to navigate through often compromised market interactions, but this constant vying for dominance of various ideals between members of a particular social group can itself serve to shape the market and practices of consumption. Thus, rather than viewing ethical consumption as a unidirectional relationship between the consumer and the market, as we argue has tended to dominate research in this area, we consider ethical consumption in terms of a relational interaction between ethically concerned consumers and the market. We consider such a focus pertinent to marketing in providing an improved understanding of how ethical consumers negotiate and manage consumption choices both within and outside ethical markets and the decisions surrounding how organizations respond to such consumer concerns. Further, exploring ethical consumption within the wider market context will provide insights into how ethical consumption may evolve in the future through an improved understanding of how ethical consumption is both shaping and being shaped by market practice.

The purpose of this paper, therefore, is to examine how ethical consumers locate themselves and their practices within and in relation to the wider market and practices 
of consumption. In the sections that follow we consider the contemporary phenomenon of ethical consumption and market engagement. This illustrates how acts of ethical consumption have occurred both as reactions to and within the extant market structure. We set out our contribution to understanding ethical consumption as a relational theory of practice to dominant notions of consumption. This is presented as a preliminary to setting out our empirical data.

\section{Ethical Consumption in the Market}

Marketing literature over recent decades has commonly used the term 'ethical consumer' to describe those who consider the environment, human and/or animal welfare as important and as a consequence evaluate their consumption lifestyles to take these issues into consideration (e.g., Strong, 1997; Harrison et al., 2005; Barnett et al., 2005). This is by no means the only term used to describe such consumers (see e.g., Shaw and Connolly, 2006 for discussion) and such terminology is extremely malleable, being applied to or appropriated by many different environmental and social justice standpoints. Individual consumer practices may vary, making the notion of a 'typical' ethical consumer hard to define. This is clearly illustrated in the varying consumer typologies presented by Gabriel and Lang (1995; 2006). Much of this literature, however, has viewed ethical consumption from the perspective of the consumer seeking to resist the market. Examples of this can be found in literature exploring consumer activism where consumer mobilisation is examined as a means to take action around the ideals of sustainability, social justice and animal welfare. Often such consumers share anti-corporate, anti-brand and anti-commercialisation sentiments which fuel their acts of resistance in relation to the market (e.g., Close and Zinkhan, 2009; Sandikci and Ekici, 2009; Hollenbeck and Zinkhan, 2006; Kozinets 
and Handelman, 2004; Thompson and Arsel, 2004; Rumbo, 2002; Bordwell, 2002; Lasn, 1999; Fournier, 1998; Penaloza and Price, 1993). Ethical consumption has also been explored as a form of political consumerism where acts of consumption and nonconsumption are explored as a means of seeking to transform the capitalist system (e.g., Stolle et al., 2006; Micheletti et al., 2004). In this sense, the construction of the 'ethical consumer' has been inherently reliant on a definition that exists in resistance to the 'mainstream' market, which represents prevalent attitudes, values and practices (see Crane, 2005 for discussion of mainstream and ethical markets). For example, the wealth of literature in the area of voluntary simplicity again frames consumer-citizens as resisting the market by reducing their consumption and market interactions (e.g., Craig-Lees and Hill, 2002; Maniates, 2002; Elgin and Mitchell, 1977).

The most pertinent example of this relationship is in research positioned within an anti-consumption framework (e.g., Close and Zinkhan, 2009; Sandikci and Ekici, 2009; Craig-Lees and Hill, 2002; Rumbo, 2002) which explicitly states that anticonsumption represents acutely held reactions to consumption generally (Zavestoski, 2002) and is "against consumption" (Lee et al., 2008: 145). This implies that individuals are seeking to eschew the market, a view which de facto places individuals outside of the market and, thus, wider society. Holt (2002) argues that consumer activism in response to the market does not result in consumer emancipation. Indeed, Kozinets (2002: 22) highlighted that "consumers are human beings, and consumption is the many human acts that people perform as they interact with the material world around them". Goods hold cultural significance (Douglas and Isherwood, 1979) and are central to how individuals express themselves. Even beyond 
fulfilling functional needs, ethical brands can be viewed as representative of authenticity, self-identity and one's social positioning within the arena of consumption. Thus, we would argue that if we accept that an individual cannot escape the market then research exploring an anti or resistant perspective should consider such practices not only as unidirectional acts of resistance but relational market interactions occurring within a wider market structure.

A number of authors have begun to show this interaction as redefining the boundaries of 'ethical consumption' as a symbolic concept. Research in this area exploring ethical consumer decision-making (e.g., Shaw and Shiu, 2003; Dickson, 2006; Shaw and Clarke, 1999; Shaw et al., 2006a) found that while ethical consumers were concerned about overall consumption levels, many believed that to reduce their consumption would lessen their power in the marketplace, due to an inability to then vote via their "purse strings" (ibid: 116). In adopting the market system to enact change, this suggests that consumption can offer a greater voice. Revealed, therefore, are consumers who are locating themselves within the market to punish those deemed to be engaging in unethical practices through boycotting and protest and to reward those considered to be displaying ethical credentials through buycotting (Friedman, 1996; 1999). The impact of this is significant: such examples can be witnessed in over $£ 4$ billion of UK consumer spending on ethically marketed food products (Williams, et al., 2005) and in boycotts against Genetically Modified Foods (Gaskell, 2000), Nestlé (e.g., Moorhead, 2007) and Gap and Nike (Tomolillo and Shaw, 2003). 
While, as argued above, much literature in the area of ethical consumption has focused on a unidirectional relationship focused on consumer actions directed at the market, other research has suggested a similar relationship in the direction of the market to the consumer, although not focusing on the quotidian processes through which this might occur. As highlighted in the ethical consumer decision-making literature, in many cases it is market engagement rather than rejection that can be witnessed in the substantial markets that have been created to represent these value alternatives. However, this resistance to one form of consumption frequently simply takes the structure of another (e.g., Arnould, 2007; Heath and Potter, 2004; Holt, 2002; Rumbo, 2002; Kozinets, 2002). Critics would argue that the so called successes of ethical consumption are merely ethical values co-opted by marketing for its own ends and that the transformative nature of ethical consumption messages have been lost as the marketing of ethical alternatives becomes focused on the concept of consumer sovereignty, placing consumer interests over producer well-being (Fridell, 2007 cited in Low, 2008). Thompson and Coskuner-Balli (2007: 137) point to such 'ethical mainstreaming' as the "beginning of its demise". They refer to consumers who pay a premium for such products as status seekers looking for "a hip guise for bourgeois consumerism" (136), rather than questioning the system of production, such practices can be criticised as merely feeding the very system it claims to be seeking to reform. This can be witnessed in the appropriation of ethical alternatives, such as fair trade, by transnational companies including Nestlé, Kraft and Cadbury's. Thus, again this suggests a unidirectional relationship, however, this time between the market coopting ethics for its own ends in offerings directed at the consumer. 
To summarise, we have argued that much of the literature exploring ethical consumption has done so from the perspective of a resistant consumer, one who is seeking to resist or reject the market, witnessed in the wealth of literature around consumer activism (e.g., Kozinets and Handelman, 2004; Thompson and Arsel, 2004), political consumption (e.g., Stolle et al., 2006; Micheletti et al., 2004), voluntary simplicity (e.g, Craig-Lees and Hill, 2002; Maniates, 2002) and anticonsumption (e.g., Lee et al., 2008; Zavestoski, 2002). In contradistinction, however, further literature exploring ethical consumption has explored market engagement through consumer voting and market embedded decision-making (e.g., Shaw et al., 2006a; Shaw and Shiu, 2003). In both perspectives, however, is a view of consumer actions directed at the market in a unidirectional relationship. In some instances ethical decisions are examined in isolation both from discussions of other consumption modes and across different practices considered under the umbrella of ethical consumption itself (e.g., Thompson and Coskuner-Balli, 2007; Dickson, 2006; Shaw et al., 2006b; Shaw and Shiu 2003). While such a response from the market has been considered a success and a failure of ethical consumption, such criticisms suggest a unidirectional relationship between a market operating to protect its own agenda and a consumer bound by its choice. We argue that it is pertinent to explore the relational interaction between ethical consumption and the wider arena of consumption and consumption practices. We argue that is this important for several core reasons. Firstly, the construction of ethical consumer decision-making in isolation has hindered our understanding of ethical consumption in a dynamic and changing marketplace where 'meaning' is subject to change. Whilst some research has revealed the tensions and challenges in upholding the subject position of an 'ethical consumer' where desired choices may not be available locally or may not 
currently exist at all in the market (e.g., Shaw and Clarke, 1999; Shaw and Shiu, 2003), in a field which is rapidly changing in relation to what 'ethical' or 'the market' may mean, it is necessary to develop a means of theoretically exploring the process through which this relationship evolves and transforms whilst taking into account the inherent tensions and contradictions individuals face when engaging in their chosen arenas of consumption. Key to this is being sensitive to the constant negotiation between the consumer and the market and the multi-directional relational interaction as opposed to a unidirectional anti-relational encounter.

Secondly, ethical consumption has arisen as a reaction against many dominant practices of consumption, however, its situatedness as within (rather than against or transcending) practices of consumption means that it is theoretically pertinent to explore the relationship between ethical consumption and the wider arena of consumption. Ethical consumption is both shaping and being shaped by the capitalistdriven market. This is illustrated in the many examples of ethical mainstreaming where mainstream business has adopted aspects of ethical practice which have shaped their business practices, while in turn some ethical businesses have been moulded by mainstream business through a need to be competitive in the market and where larger mainstream companies have bought over ethical niche players (Crane, 2005). Such changes in the market highlight the need to understand the dynamic interaction between ethical and mainstream markets and how this shapes markets both now and in the future.

Finally, there has been an assumption that ethical consumers and ethical consuming are discreet categories that fit together with no contestation or contradictions in an 
individuals identity work. We argue for a change in focus from critiquing ethical consumption as a resistant and isolated practice, towards a need to understand the tensions involved in participating in consumption which crosses the boundaries between ethical and mainstream where there appear to be contradictions between ideals and behaviour, and the processes involved in negotiating such practices. The purpose of this paper, therefore, is to conceptualise the relationship between ethical and capitalist-driven modes of consumption, thus, enabling an exploration of the multidirectional dynamics between ethical consumption and the larger arena of consumption, and consider the situated subject position of 'the ethical consumer'. In light of this, we now move onto an empirical analysis of how individuals locate and negotiate their practices of ethical consumption in relation to wider practices of consumption.

\section{Methodology}

Given that little empirical research has explored how individuals negotiate between ethical consumption and the mainstream market within a multidirectional paradigm, a research framework that allows for exploratory research was necessary. This study has, therefore, adopted a qualitative approach based on phenomenological interviews with known ethical consumers in a New Zealand city which explores the meanings underlying consumer actions (Blumer, 1969; Denzin and Lincoln, 1998). Using guided introspection (Wallendorf and Brucks, 1993) participants were asked about themselves and their actions and their responses were recorded and transcribed verbatim. Interviews were conducted with seven volunteer participants. Such small sample sizes are in keeping with previous research (e.g., Thompson, 1997; Connolly and Prothero, 2003). The nature of the research focus necessitated the use of an 
accentuated sample where ethical concerns in relation to consumption existed. All interviews commenced with a 'grand tour question' (McCracken, 1988) about any issues of concern in consumption, beginning the interview in an open-ended format (Thompson et al., 1989). During the dialogue participants were encouraged to describe their actual experiences and actions, ensuring a conversational quality. All participants were assured of anonymity.

Analysis of the interview transcripts followed a process of interpretation as outlined by previous research (e.g., Thompson, 1996). Transcripts were read to develop a holistic understanding of participant narrative and this was further informed by subsequent readings, documenting and systematizing. The process of noting key phrases and patterns of meaning enabled the transcripts to be further analyzed to develop thematic categories and identify holistic relationships among the meanings and categories participants used to describe their consumption experiences and actions. From this analysis emerged three key themes that were drawn upon by participants as a means of understanding their own practices within the wider arena of consumption in their practice as ethical consumers.

\section{Findings and Discussion}

Participants experienced a dynamic relationship in terms of reacting to both the espoused logic of the market and their on-going self-construction as ethical consumers, however, three themes highlighted how the construction of ethical consumption occurred through a relational process to the dominant market. Firstly, ethical consumption as a practice was co-constructed in relation to the subject position of 'being' an ethical consumer. Secondly, this served to help participants create a 
narrative that built a relationship between ethical and dominant spaces of consumption where the potential for change could occur. Finally, analysis showed the interaction across spaces of consumption as seeking to advance the praxis of ethical consumption.

\section{$\underline{\text { Identifying the Ethical Consumer }}$}

In constructing the space of ethical consumption participants were extremely careful in shaping the connection between 'being' ethical consumers as an ontological subject position and 'ethical consumption' as a mode of practice. This view went beyond the act of buying ethically and instead focused upon what we might see as a collective habitus (Bourdieu, 1977). As Pierre Bourdieu discusses, through being biographically constructed, the habitus is a link between an individual's unique identity, and shared dimensions with others (such as class, or ethical lifestyle) that help us to associate or attach ourselves with certain individuals or feel we 'belong' in particular social contexts. This dimension was crucial in the identification of 'fellow members' of the ethical consumption movement who in turn, could help to modify or reproduce practice. This idea appeared particularly strong amongst participants with a notion of a 'collective' identity of ethical consumers who identified themselves as key stakeholders:

I'm part of the Duncan community and more specifically the North Duncan or even the North East Vale community. And I know a lot of people in my life, friends that I've been to school with and so on, and just bump into them in the supermarket and see them from time-to-time. Yeah. And then I'm part of specific interest communities like the Green Party or the Soil and Health 
Association or Forest and Bird Society or the Lesbian and Gay Community and my uhm...Witches Coven (Penny).

Penny shows that the construction of her 'ethical consumption' identity draws on more than simply her consumption practices, but other communities where kindred ideologies were upheld. This was further enforced through participants creating a 'them' against 'us' viewpoint, whether that opposition be towards those they considered as following the rationale of dominant consumption, or larger bodies of political power. The shared sense of identity could therefore be capitalized through groups offering solidarity in challenging those in power (Taylor and Whittier, 1992), whilst offering the flexibility to draw on or capitalize on difference spaces of autonomy depending on the struggles or challenges faced. Penny continues:

...you have to work with what's happening. But at the same time I feel that, I guess I feel like I'm on, I'm maybe on a fringe, you know maybe a bit of a cutting edge if you like uhm, of a movement towards ethical consumption of, you know what I see as ethical consumption. But I feel it's essential to have that, those people on the edge pulling people forward and pulling in that direction otherwise we're never going to get there.

As with other participants, this overall set of values inculcated within their habitus, led to a more general 'world view' where consuming ethically was part of a wider conglomeration of practices that distinguished what they were not. This appeared to be aligned with what may be regarded as dominant market ideals. Mandy, for 
example, described listening to a marketing lecture in university about brand recognition and loyalty as "listening to someone else's religion". Similarly, many conflated the notion of consuming ethically with wider concerns over health and organic production and lifestyle values of spiritual and political ideals that all constituted part of the participant's strive for authenticity of the self (Giddens, 1991). This did not mean always questioning the doxic logic of dominant consumption in terms of the act of buying in itself, but rather mediating the notion of making informed choices about what they bought and who they bought from:

I think if you're going to have GE then you need to tell people 'this is GE and this is not', so people can still make a choice, and this it only seems fair to me, if you want to live in a certain way, but you can't because you don't even know what's in what food, that's not very, I don't think that's a very good democratic society...You're not told the full facts, so that you don't get too spooked out about what's in food. That's not fair you should be told what, you should have the informed choice...and there's so much people don't know. And it is scary and there's a lot of people who don't want to know, because the more they know, they realise that they can't do anything about it and what they eat is crap. So, yeah, I guess, I try and go to things like the farmers market and try and you know, just support, even though it's expensive, support things that are labelling GE free, because I want to encourage that and labelling things organic or labelling things local or whatever, to try and encourage that (Mandy). 
It appeared that although by entering spaces of consumption players must to a certain extent accept the implicit 'rules of the game', there was continual contestation and negotiation over what may be deemed legitimate practice by an 'ethical consumer'. For many participants, a key part of this was interacting with the dominant market in order to shape it in a way that might influence those fully ascribed to capitalist market ideals. Aware of appealing to those with a different set of priorities, participants, as shown in Mandy's excerpt, attempt to marginalise the economic implications of alternative choices in a strategic attempt to transfer symbolic value away from economic capital (the price of a product), towards cultural capital (knowledge about the origin, quality or ethicality of food production). In doing so, respondents appeared to attempt a shift in the ingrained assumptions made about market activity. However, there is also the assumption that if the mainstream market adopted ethically driven notions of 'choice' then others would become converted to an 'ethical way of thinking'. In this sense, there was an underestimation of the importance of the ideological tenets of ethical consumption and how easily they may be transposed into the thinking of others, 'if only they knew'.

\section{Situating the Practice of Ethical Consumption}

While each participant had a strong notion of the parameters of ethical consumption, there was widespread acknowledgement concerning the difficulty in exclusively inhabiting 'ethical spaces'. It was clear that, contrary to the implicit dichotomy drawn by many scholars who examine ethical consumption behaviours in isolation (see e.g., Harrison et al., 2005), participants had to occupy and participate within the wider field of consumption: 
I don't know, it's something that you don't want to be involved in but then you are. All the time everyday, I mean it's almost every day that you end up opening your wallet to purchase something or are involved in the marketplace in some way. So it's sort of like, it's hard to get away from it unless you lived a very isolated lifestyle. It's very hard to live outside, so you've got to make the best of it and your relationship to it (Mandy).

While a reversal or defiance of commodification was an ambition of most participants, for many it remained a distant goal. Rather, in their narratives, participants would promote strategies of reducing consumption. For example, participants discussed 'making do and mending' by making items last longer (Durning, 1992; Papanek, 1995) and reused many items as a means of justifying an initial participation in the market whilst not compromising their own self-identity as an 'ethical consumer'. Again these colluded with wider lifestyle or political choices. For example, responding to economic and animal welfare concerns, participants sought to modify their diets to varying degrees. Some had reduced their meat consumption and/or purchased free-range or organic animal products. Others had adopted a vegetarian or vegan diet.

Thus, all participants were seeking to enact strategies to address the extent of their consumption, being careful to negotiate a sense of self in the face of behaviour that may be deemed 'unethical'. This is in sharp contrast to Shaw et al. 's (2006a) study of UK ethical consumers which found a strong focus on modifying consumption through marketplace encounters. Despite an emphasis on consumption reduction, however, much of their consumption still took place within the main market system, thus, 
requiring that they place emphasis on the nature of their consumption in terms of their concerns about the local and wider environment, people and animals. As a result, particular behaviours were diverse but reflected similar practice across participants where tensions in desired market interactions often existed:

I went into this shop and he said can I help you and I said, probably not I want something that's cheap, stylish, umm, not made by a sweatshop and it was probably an orphan made it probably. And I just knew immediately that I'd have to make some compromises, so it was made in a sweatshop but everything in that shop was (Jane).

And how did you know, did he say these are made in a sweatshop? (Interviewer)

No but one assumes they're made in China or Vietnam, but they are...Yes, I mean it's not infallible but it's a guide. Also the price of it obviously, and quite a nice pair of shoes, high heel shoes for $\$ 30$ [16 Euro], umm yeah (Jane).

The market for ethical clothing is less developed in terms of ethical alternatives when compared to food and similar findings have been found elsewhere in clothing choice (Shaw et al., 2006b). Jane found her ideal choice lacking and, thus, presents herself as forced to use 'imperfect clues' to inform her decision. Rather than the practice of telling the market what she desires through her purchase votes (e.g., Dickinson and Hollander, 1991; Shaw et al., 2006a) she experiences her market engagement as 
imprecise and ineffective. Despite such uncertainty and, thus, tension between the capitalist-driven spaces of consumption and ethical consumption, participants felt compelled to act even if their goal in terms of contributing to the general good was in question. Therefore, the focus of narratives was often diverted from the purchasing decision towards micro-processes of interaction that occurred during the purchase, such as challenging sales assistants.

Participant's narratives also highlighted the importance of recognising the various power dynamics at play within consumption practice, and the danger of reproducing, rather than radicalising social practices. For many participants, the imbalance of power towards market providers required placing emphasis on whether the outcome of the markets 'ethical' endeavours were more important than considering the markets economically-driven objective for engaging in ethical practice in the first place. In this sense, it is impossible to view ethical consumption as severed from other modes of consumption, since our participants are following a similar doxa in terms of 'buying as power' as seen in other consumption practices. Whilst an individual may seek to become 'anti' in the sense of polarizing oneself against notions of consumption they abhor, they are still caught up within tensions over choices of how to consume in relation to what the dominating forces of the field provide. However, even although ethical consumption fails in having its own autonomy this does not render it a proverbial puppet to its master. Rather, it is through individual and collective struggle that continually sets the parameters and makes meaning over what is constituted as 'ethical practice' within the dominant market.

\section{Practicing What You Preach}


Participants actively situated themselves as marginalised by a consumer culture structured by marketing activities (Holt, 2002) and one which embraced hyperconsumption (Kilbourne et al., 1997). An unwillingness to define oneself through mainstream consumer culture was common to all participants, revealing the strong conviction with which values were held. As discussed above, however, the construction of consumption spaces often served to challenge what was deemed an act of ethical consumption and required legitimation from the purchaser's background. However, it may be argued that the creation of such boundaries are necessary since the competing orthodoxies serve to further develop ethical consumption as a movement, rather than simply acts of consuming. This certainly appeared to be the case in the participants' narrative where other characteristics of their lifestyle were seen as shaping and affecting the definition of ethical consumption. Again, participants framed these activities as being on the margin of normative lifestyle practices where wider lifestyle choices were inherently connected to the spaces of ethical consumption are illustrated by Karen:

Jason [partner] and I have talked about it quite a lot because he does, like he's a gardener, and he does lots of gardening, so we are growing quite a lot of our food with vegetables and its like, well you could work more and then we'd have less time, to buy more of our food. But then its like, well maybe the amount of time it might take him to grow food, if you put it altogether it wouldn't be a very high hourly rate that he got paid, if we then went out and bought all our food, then it sort of wouldn't really compare. But you know it's kind of like, make your decision. But it's better to have a bit more time then to be able to be outdoors for him to do gardening for us (Karen). 
The practices adopted by Karen and her partner are reflective of both voluntary simplicity (Etzioni, 1998) and downshifting (Schor, 1998) highlighting wider lifestyle concerns that impact upon the spaces of ethical consumption and, thus, which are not in themselves exclusive practices and choices. Karen reflects on their 'superior' decision to have more time outdoors to do their own gardening, revealing quality of life as an important motivation even although it may reduce household income. Karen and her partner did have the capacity to enhance their income so they could afford to purchase their food within the market system, but voluntarily opted out of commodification. In this sense Shaw and Newholm (2002) would refer to Karen as an ethical simplifier, as in addition to behaviours reflective of voluntary simplicity and downshifting she was seeking to respond to social and environmental problems through reducing her role in consumer society. Karen, thus, can be seen to draw on capital from other sources of existence in advancing her participation in and definition of ethical consumption.

Yet, this 'practicing what you preach' trope served to build the ethical consumer identity as produced through individuals locating themselves on the margins of political, social and cultural practices:

......I'd been campaigning against genetic engineering for about five years starting, there was the Royal Commission on genetic modification (as they called it) that the government set up and that was uhm to, to look at the whole issue, to canvas opinions around the country and they had, the 
Commission had a series of meetings and I went along to those and I put in a submission to the Commission at that time and that didn't really seem to have much effect. The Commission came out with a really wishy-washy statement, something to the effect of: the government could pursue genetic engineering with caution...So anyway the issue just carried on and then it was when the Moratorium on growing GE crops in New Zealand was about to be lifted and there was a lot of uh...activism and protests. I mean we had 10,000 people marching in Auckland about the issue. Uhm, and that's when I wrote a submission...And basically I mean, the same old arguments...throws up enough question marks about the effects on human health, animal health, environmental health, uh let alone, you know the economics. I mean New Zealand, I think you know we've got this clean green reputation and if we sullied it with GE then it would just ruin it, that's what I think, you know. So even if they didn't listen to all the other things they might listen to the economic argument. I don't know how worthwhile it was. I mean it was really good for me, I felt really powerful sitting there at the table with these politicians, these MPs, looking them in the eye...I think they respected me but you know, I think most of them were already sort of bound to vote along party lines as to what their party policy was and I don't know how much effect it had, but I still think that we've got to keep doing that otherwise, we might as well just lie down and you know, commit suicide or something. We've got to have hope. Yeah. We've got to have hope. We've got to keep acting because I think in New Zealand too, because we're such a small country, you know, only four million people, one person can make a difference (Penny). 
Penny's actions are clearly seeking a countervailing of power (Pestoff, 1988) and a rebalancing of sovereignty and go beyond the action of 'buying' towards a political arena which seeks to advance and shape her practice. Polletta and Jasper (2001) reflect on the existence of expressive and strategic displays of activist identity. Penny's approach is also expressive and organized as an instrument of voice. She felt empowered and sought not to escape from the situation that troubled her but to influence the decisions and behaviour of others. Similarly, Flora regularly voiced her concerns to companies in the form of praise or reprimand believing that as a sovereign consumer they are obligated to respond to her demands. Her belief was that consumer sovereignty will have an economic impact and she sought to impose change within the existing market system through modified consumption. Such actions were reflective of Hirschman's (1970) Exit, Voice and Loyalty. Exit illustrated through the foregoing of consumption and renouncing a product's (perceived) negative attributes and consequences. Loyalty illustrated in support for alternatives such as fair trade products where the negative consequences of the consumption are attenuated or eliminated. Finally, voice was used to attempt to alter institutions and systems employing a range of political devices.

It appeared that ethical consumption as an act was not only about practicing, but also being part of a group who voice their opinions and actively attempted to facilitate change, not least through their personal acts of consumption. This 'practicing what you preach' trope compliments a more generative model of social change, where action (rather than doctrine) has the ability to attempt a subversion of conventional practice. It is unsurprising, however, that individuals were wary of being socially 
reprimanded, sometimes the tensions among spaces of consumption practice where challenging. Kathleen, for example, feared isolation through her practices in relation to ethical consumption which might result in internal conflict and a desire not to be viewed as a "severe type person", while holding the awareness that she was ignoring the lack of substance she found in the dominant consumption paradigm.

\section{Conclusion}

In seeking to explore the lived experiences of those constructing ethical consumption through negotiating the pathways within and between various consumption and lifestyle choices, this paper has sought to make several contributions to the literature within the arenas of resistant and ethical consumption. Firstly, this paper has developed a conceptualisation of the relationship between the mainstream market and ethical consumption as constructed by the process and practices of individuals, rather than assume an a priori distinction. Secondly, through focussing on the multidirectional dynamics at the level of practice, it reveals the conflicts, contradictions and strategies that result from individual's practices that can attempt to shape and transform both ethical and mainstream spaces of consumption. Finally, it has showed the need to understand how ethical practices that are not strictly consumptive can gain legitimacy and power through a collective 'habitus' of those occupying particular spaces. Moreover, these spaces can be viewed as not 'on' the margin but 'in' the margin.

In seeking to understand the spaces occupied, the practices of the participants reflected the logic of Pierre Bourdieu's field theory (1988). According to Bourdieu, a field is an abstract space (rather than place); a social arena in which members 
inhabiting the field are involved in a struggle over the acquisition and constitution of legitimacy, influence and authority (Bourdieu and Wacquant, 1992: 105). The promotion of ethical consumption as a separate field, as is inferred from a number of recent studies (e.g., Harrison et al., 2005) is problematic, since ethical consumption operates on the 'logic' of consumption, in terms of exchange of goods, and involves many of the same actors and objects, such as producers and consumers. Moreover, obtaining the product still forms an important constituent of defining both ethical and mainstream forms of consumption and the distribution of power in terms of the relationship between consumer and producer is often a reaction against (rather than entirely separate or autonomous from) more mainstream forms of consumption. Therefore, Bourdieu's notion of sub-fields as a metaphor for locating ethical consumption within the wider arena of consumption is of key importance. One of the key characteristics of the field is its autonomy relative to other fields (Bourdieu, 1984); a separate universe (Bourdieu, 2000: 19) where legitimation is consecrated by and through the dynamics of the field itself. A sub-field on the other hand is situated within a field and not only mirrors the action of that field but, crucially, may go against the orthodoxic practice of the main field. For example, in his discussion on art, Bourdieu sees the emergence of the artistic field as historically situated in a break from patronage towards more liberal parameters (Bourdieu, 1983). Similarly, in our study, we can see that the sub-field thesis reflects participants' potential to both break away from and patronise the mainstream market, thus opening up a theoretical vista through which we can explore ethical consumption and the market within a dynamic paradigm. 
Bourdieu's thesis also helps us to conceptualise the role of other communities as feeding into the construction of ethical consuming and the subject position of the ethical consumer. Clearly revealed, therefore, are the limitations of exploring the action of one particular social arena (such as consumption) in isolation. In occupying a number of fields consecutively, it appears that whilst Bourdieu's notion of 'field autonomy' still stands, there is evidence that acts of ethicality performed within other fields, such as the workforce or lifestyles, could be used as a means of strengthening the legitimacy of the practices of ethical consumption. In this sense, 'capital exchange' could occur, where resources in one field gained a value within another field. Individuals moving in and out, and between various fields, can actively carry over forms of legitimacy (as seen in the case of participants in various social groups of political activist communities) and use them to transform other fields of practice, such as the field of consumption. This allows for a more relational analysis of the tensions, contradictions and impacts that we saw existing between ethical and other consumption modes and how they are played out at the level of individual practice for those participating within the field. As a result, instead of concentrating on the physical or material dimension of the object, the focus becomes a nebulous process of socially created symbolic production. In relation to this, ethical consumption is situated in a complex world view where 'choice' becomes not simply a market ideal but a key tenet in how ethical consumers define, mould and create themselves and others.

This inherent tension which serves to co-construct these contrasting orthodoxies inevitably affected the subject position of our participants. New subjects, objects and concepts continually entering and leaving a field mean that subject positions must be 
constantly negotiated in order for small shifts in the conceptualization of the field to take place. The difficulties in occupying the spaces within and between fields were evident in the continual struggle to set the parameters around ethical practice. This transferred into the identities of our participants where the ability to be fluid, unsettled and move between different circles and communities was not only an identity strategy, but was required in order to transform or change the field of consumption. Polletta and Jasper (2001: 10) describe collective identity as "fluid and relational, emerging out of interactions with a number of different audiences". Yet more significantly, these ethical consumers seemed to be most at ease with locating themselves 'in the margins' of various fields. In this sense, we may argue that the identity of an 'ethical consumer' is not only about being situated within a number of fields but also creating spaces between them. Part of this may of course be a preservation tactic. On discussing Bourdieu's field theory, Martin (2003) argues that struggle is not only over the rules, but within the rules. This in turn means that any form of subversion that seeks to challenge the field's doxa can be 'punished' by others who subscribe to the field unquestionably. In resisting full appropriation to a field, ethical consumers use a position of ambiguity to create their own sense of collective self, which can be sustained as long as the capitalist-driven markets of consumption are positioned as the norm. Not only does this mode of abjective identity create a subcultural space where vocabularies of consumption and lifestyle can be mutually reconfigured, but it also affords the participant an ability to 'visit' the field whilst not compromising their own sense of self.

Ethical consumption through the lens of fields and the margins created between them provides the potential for autonomy or power to define value as set within the basic 
tenets of consumption, where ethical consumption practices can be seen as consecutively constructed both in opposition to, and within, marketplace encounters. The tensions evident in practices of ethical consumption mean that such actions are not practiced in isolation to the concerns of consumption in the wider field of consumption. Rather, ethical consumption should be viewed relationally, concentrating on the 'in between' created by particular concepts or spaces of practice. This positionality allows influence without full appropriation to the dominant field and subscription to the 'rules of the game'. To an extent this influence can be witnessed in the 'mainstreaming' of ethical ideals such as fair trade, animal welfare and environmental concern. Until fairly recently many of these issues were deemed to be a concern of a minority now, however, such issues are reflected in the availability of product alternatives and practices of mainstream retailers. To this extent we concur with Starhawk (2004: 37, cited in Scott and Penaloza, 2006) that "change in systems often comes from the edge", and argue that ethical consumption practices have the potential to make a real and lasting impact to market practices. Indeed, participant Penny located herself "on the fringe" as "cutting edge...pulling people forward". Although it may be that a move of 'ethical' into mainstream arenas comes with the danger of the message becoming a diluted, capitalist-led construction that only reinforce market ideals, rather than challenging the choices we make in our consumption practices, we must recognise the balance sought between reduced consumption as ethical and continued but modified consumption as ethical. For much of ethical consumption an anti-consumption stance is not a cultural or political feasibility. Rather than a focus on less or denying the pleasures of consumption choices can be used to address questions of morality and meaning. Soper (2007) suggests 'alternative hedonism' as an alternative to promote the pleasures of 
alternative and reduced consumption. Such practices were in evidence in the current research and highlight the potential for further interaction of values and practice from a position of ethical consumers in relation to consumption.

\section{References}

Arnould, E. J. (2007), “Should Consumer Citizens Escape the Market?”, American Academy of Political \& Social Science, Vol. 611 No. 1, pp. 96-111.

Barnett, C., Cloke, P., Clarke, N. and Malpass, A. (2005), "Consuming Ethics: Articulating the Subjects and Spaces of Ethical Consumption", Antipode, Vol. 37 No. 1, pp. 23-45.

Beck, U. (1992), Risk Society: Towards a New Modernity, Sage, London.

Blumer, H. (1969), Symbolic interactionism: perspective and method, Prentice-Hall, Englewood Cliffs, NJ.

Bordwell, M. (2002), “Jamming Culture: Adbusters’ Hip Media Campaign against Consumerism", in Princen, T., Maniates, M. and Conca, K. (Eds), Confronting Consumption, The MIT Press, London, pp. 237-254.

Bourdieu, P. (1983), "The field of cultural production, or: the economic world reversed", Poetics, Vol. 12 Nos. 4-5, pp. 311-356.

Bourdieu, P. (1984), Distinction, Routledge, London. 
Bourdieu, P. (1988), Homo Academicus, Polity, Cambridge

Bourdieu, P. (2000), Pascalian Medications, Polity, Cambridge.

Bourdieu, P. and Wacquant, L. (1992), An Invitation to Reflexive Sociology, Polity, Cambridge.

Campbell, C. (1995), “The sociology of consumption”, in Miller D (Ed.)

Acknowledging. Consumption: a review of new studies, Routledge, London, pp. 96126.

Cherrier, H. (2008), “Anti-consumption discourses and consumer-resistant identities”, Journal of Business Research, Vol 62 No 2, pp. 181-190.

Close, A. G. and Zinkhan, G. M. (2009), "Market-resistance and Valentine's Day events", Journal of Business Research, Vol 62 No 2, pp. 200-207.

Connolly J. and Prothero, A. (2003), "Sustainable Consumption: Consumption, consumers and their commodity discourse", Consumptions, Markets and Culture, Vol. 6 No 4, pp. 275-291.

Craig-Lees, M. and Hill, C. (2002), "Understanding Voluntary Simplifers", Psychology and Marketing, Vol. 19 No. 2, pp. 187-210. 
Crane, A. (2005), "Meeting the Ethical Gaze: Challenges for Orienting to the Ethical Market", in Harrison R, Newholm T and Shaw D (Eds) The Ethical Consumer, Sage, London, pp. 219-232.

Denzin, N. K. and Lincoln, Y. S. (1998), Strategies of Qualitative Inquiry, Sage, London.

Dickinson R. and Hollander, S. C. (1991), "Consumer Votes”, Journal of Business Research, Vol. 22, pp. 335-346.

Dickson, M. (2005) “Identifying and Profiling Apparel Label Users", in Harrison, R., Newholm, T. and Shaw, D. (Eds.), The Ethical Consumer, Sage: London, pp. 155172.

Douglas, M. and Isherwood, B. (1979), The World of Goods, Basic, New York.

Durning, A. (1992), How much is enough? The consumer society and the future of the earth, Earthscan, London.

Elgin, D. and Mitchell, A. (1977), "Voluntary Simplicity”, Co-Evolution Quarterly, Summer, pp. 1-40.

Elliott, R. (1997), “Existential consumption and irrational desire”, European Journal of Marketing, Vol. 19, No 3 / 4, pp. 285-96. 
Ethical Consumer, 1989, Vol. 1 No. 1, pp. 7.

Etzioni, A. (1998), "Voluntary simplicity characterization, select psychological implications, and societal consequence", Journal of Economic Psychology, Vol. 19, pp. 619-643.

Featherstone, M. (1995), Undoing culture: globalisation, postmodernism and identity, Sage, London.

Fournier, S. (1998), "Consumer resistance: societal motivations, consumer manifestations, and implications", Advances Consumer Research, Vol. 25 No. 1, pp. $88-90$.

Friedman, M. (1996), “A positive approach to organized consumer action: the 'buycott' as an alternative to the boycott", Journal of Consumer Research, Vol. 19 No. 4, pp. 439-451.

Friedman, M. (1999), Consumer Boycotts: Effecting Change Through the Marketplace and the Media, Routledge, London.

Gabriel, Y. and Lang, T. (1995, 2006), The Unmanageable Consumer, Sage, London.

Gaskell, G. (2000), “Agricultural Biotechnology and Public Attitudes in the European Union”, AgBioForum, Vol. 7 Nos. 1 and 2, pp. 87-96. 
Giddens, A. (1991), Modernity and Self Identity, Cambridge, Polity.

Harrison, R., Newholm, T. and Shaw, D. (2005), The Ethical Consumer, Sage, London.

Heath, J. and Potter, A. (2004), Nation of Rebels: Why Counterculture Became Consumer Culture, Harper Business, US.

Hirschman, A. O. (1970), Exit, Voice and Loyalty, Harvard University Press, USA.

Hollenbeck, C. R. and Zinkhan, G. M. (2006), “Consumer Activism on the Internet: The Role of Anti-brand Communities", Advances in Consumer Research, Vol. 33, pp. 479-485.

Holt, D. B. (2002), "Why do brands cause trouble? A dialectical theory of consumer culture and branding", Journal of Consumer Research, Vol 29, pp. 70-90.

Kilbourne, W. McDonagh, P. and Prothero, A. (1997), "Sustainable consumption and the quality of life: a macromarketing challenge to the dominant social paradigm", Journal of Macromarketing, Vol. 17 No. 1, pp. 4-23.

Klein, J. G. Smith, N. C. and John, A. (2004), "Why we Boycott: Consumer Motivations for Boycott Participation”, Journal of Marketing, Vol. 68 No. 3, pp. 92109. 
Kozinets, R. V. (2002) "Can consumers escape the market? Emancipatory illuminations from Burning Man”, Journal of Consumer Research, Vol 29 No 1, pp. 20-39.

Kozinets, R. V. and Handelman, J. M. (2004) "Adversaries of Consumption: Consumer Movements, Activism, and Ideology", Journal of Consumer Research, Vol 31, pp. 691-704.

Lasn, K. (1999), Culture Jam, Harper Collins, New York.

Lee, M. S. W. Fernandez, K. V. and Hyman, M. R. (2008), “Anti-consumption: An overview and research agenda", Journal of Business Research, forthcoming.

Low, W. (2008), "Dance of the Veils: conceptualizing commercial fair-trade", Revue Économie et Solidarités, in press.

Low, W. and Davenport, E. (2006), "Mainstreaming fair trade: adoption, assimilation, appropriation", Journal of Strategic Marketing, Vol. 14, pp. 315-327.

Martin, J. L. (2003), "What is field theory?”, American Journal of Sociology, Vol. 109 No. 1, pp. 1-49 
Maniates, M. (2002), "In Search of Consumptive Resistance: The Voluntary Simplicity Movement", in Princen, T., Maniates, M. and Conca, K. (Eds), Confronting Consumption, The MIT Press, London, pp. 199-236.

McCracken, G. (1988), The Long Interview, Sage, Newbury Park, CA.

Mesure, S. and Owen, J. (2007), "Organic Cotton Boom Hits the High Street", The Independent, 22 July http://environment.independent.co.uk/green_living/article2790966.ece

Micheletti, M., Follesdal, A. and Stolle, D. (2004), Politics, Products and Markets Exploring Political Consumerism Past and Present, Transaction, New Jersey.

Miles, S., Anderson, A. and Meethan, K. (2002) The Changing Consumer: Markets and Meanings, Routledge, London.

Moorhead, J. (2007), “Milking it”, Guardian, 15 May

http://business.guardian.co.uk/story/0,,2079864,00.html

http://www.nike.com/nikebiz/nikeconsidered/

O’Shaughnessy, J. and N.J. O’Shaughnessy (2002), “Marketing, the consumer society and hedonism", European Journal of Marketing, Vol. 36, No. 5/6, pp. 524-547. 
Oakes, L. S., Townley, B. and Cooper, D.J. (1998), "Business planning as pedagogy: language and control in a changing institutional field" Administrative Science Quarterly, Vol. 43, No. 2, pp. 257-292.

Oygard, L. (2000), “Studying food tastes among young adults using Bourdieu's theory", Journal of Consumer Studies and Home Economics, Vol. 24 No. 3, pp. 160169.

Papanek, V. (1995), The GreenIimperative, Thames and Hudson, London.

Penaloza, L. and Price, L. L. (1993), "Consumer resistance: a conceptual overview”, Advances Consumer Research, Vol. 20 No. 1, pp. 123-128.

Pestoff, V. A. (1988), "Exit, Voice, and Collective Action in Swedish Consumer Policy", Journal of Consumer Policy, Vol. 11, pp. 1-27.

Polletta, F. and Jasper, J. M. (2001), “Collective identity and social movements", Annual Review of Sociology, Vol. 27, pp. 283-306.

Rudé, G. (1981), The Crowd in History 1730-1848, Lawrence \& Wishart, London.

Rumbo, J. D. (2002), “Consumer resistance in a world of advertising clutter: The case of Adbusters", Psychology and Marketing, Vol. 19 No. 2, pp. 127-210. 
Sandikci, Ö. and Ekici, A. (2009), "Politically motivated brand rejection", Journal of Business Research, Vol.62 No. 2, pp. 208-217.

Schor, J. (1998), The Overspent American, Basic Books, New York.

Scott, L. M. and Penaloza, L. (2006), "Matriarchal Marketing: A Manifesto", Journal of Strategic Marketing, Vol. 14, pp. 57-67.

Shaw, D. S. and Clarke, I. (1999), "Belief formation in ethical consumer groups: an exploratory study", Marketing Intelligence and Planning, Vol. 17 No. 2, pp. 109-120.

Shaw, D. S. and Connolly, J. (2006), "Identifying Fair Trade in Consumption Choice", Journal of Strategic Marketing, Vol. 14 No. 4, pp. 353-368.

Shaw, D. S. and Newholm, T. (2002), "Voluntary Simplicity and the Ethics of Consumption". Psychology and Marketing, Vol. 19 No. 2, pp. 167-185.

Shaw, D. and Shiu, E. (2003), "Ethics in Consumer Choice: A Multivariate Modelling Approach", European Journal of Marketing, Vol 37 No 10, pp. 1485-98.

Shaw, S. Newholm, T. and Dickinson. R. (2006a), "Consumption as Voting: an Exploration of Consumer Empowerment", European Journal of Marketing, Vol. 20 No. 9. pp. 1049-1067. 
Shaw, D. S., Hogg, G., Wilson, E., Shiu, E. and Hassan, L. (2006b), "Fashion Victim: The Impact of Fair Trade Concerns on Clothing Choice", Journal of Strategic Marketing, Vol. 14 No. 4, pp. 423-436.

Soper, K. (2007), 'Re-thinking the 'Good Life': The Citizenship Dimension of Consumer Dissatisfaction with Consumerism”, Journal of Consumer Culture, Vol. 7 No. 2, pp. $205-229$.

Stolle, D., Hooghe, M. and Micheletti, M. (2006), "Politics in the Supermarket: Political Consumerism as a Form of Political Participation", International Political Science Review, Vol. 26 No. 3, pp. 245-269.

Strong, C. (1997), “The problems of translating fair trade principles into consumer purchase behaviour", Marketing Intelligence \& Planning, Vol. 15 No. 1, pp. 32-37.

Swartz, D (1997), Culture and Power: The Sociology of Pierre Bourdieu, The University of Chicago Press, London.

Taylor, V. and Whittier, N. E. (1992), "Collective identity in social movement communities: lesbian feminist mobilization”, in Morris, A. and Mueller, C. (Eds.), Frontiers in Social Movement, Yale University Press, New Haven, CT.

Thompson, C. J. and Coskuner-Balli G. (2007), “Countervailing Market Response to Corporate Co-optation and the Ideological Recruitment of Consumption Communities", Journal of Consumer Research, Vol. 34, pp. 135-152. 
Thompson, C. J. and Coskuner-Balli G. (2007), "Enchanting Ethical Consumerism: The Case of Community Supported Agriculture", Journal of Consumer Culture, Vol. 7 No. 3, pp. 275-303.

Thompson, C. J. and Arsel, Z. (2004), “The Starbucks Brandscape and Consumers' (Anticorporate) Experiences of Glocalization", Journal of Consumer Research, Vol. 31, pp. 631-642.

Thompson, C. J. (1997), "Interpreting consumers: a hermeneutical framework for deriving marketing insights from the texts of consumers' consumption stories", Journal of Marketing Research, Vol. 34 No. 3, pp. 438-455.

Thompson, C. J. (1996), “Caring consumers: gendered consumption meanings and the juggling lifestyle”, Journal of Consumer Research, Vol. 22 No. 4, pp. 388-407.

Thompson, C. J., Locander, W. B. and Pollio, H. R. (1989), "Putting consumer experience back into consumer research: the philosophy and method of existential phenomenology”, Journal of Consumer Research, Vol. 16 No.2, pp. 133-146.

Tomolillo, D. A. C. and Shaw, D. S. (2003), "Undressing the Ethical Issues in Clothing Choice", Journal of New Product Design and Innovation Management, Vol. 15, No. 2. 
Wallendorf, M. and Brucks, M. (1993), "Introspection in Consumer Research: Implementation and Implications", Journal of Consumer Research, Vol. 20, pp. 339259.

Williams, S., Taylor, J. and Howard, M. (2005), The Ethical Consumerism Report, The Cooperative Bank, UK.

Zavestoski, S. (2002), “Guest editorial: Anticonsumption attitudes”, Psychology and Marketing, Vol. 19 No. 2, pp. 121-126. 